BULLETIN Bulletin hispanique

HISPANIQUE Université Michel de Montaigne Bordeaux

119-2 | 2017

La Égloga renacentista en el Reino de Nápoles

\title{
Eugenia Fosalba (estudio y notas), El Abencerraje
}

Real Academia Española (Biblioteca Clásica de la Real Academia

Española, 33), Madrid, 2017

Daniel Fernández Rodríguez

\section{OpenEdition}

1 Journals

\section{Edición electrónica}

URL: http://journals.openedition.org/bulletinhispanique/5236

DOI: 10.4000/bulletinhispanique.5236

ISSN: 1775-3821

\section{Editor}

Presses universitaires de Bordeaux

\section{Edición impresa}

Fecha de publicación: 1 diciembre 2017

Paginación: 773-778

ISBN: 979-10-300-0218-8

ISSN: 0007-4640

Referencia electrónica

Daniel Fernández Rodríguez, «Eugenia Fosalba (estudio y notas), El Abencerraje», Bulletin hispanique [En línea], 119-2 | 2017, Publicado el 28 noviembre 2017, consultado el 13 enero 2021. URL: http:// journals.openedition.org/bulletinhispanique/5236 ; DOI: https://doi.org/10.4000/bulletinhispanique. 5236

Este documento fue generado automáticamente el 13 enero 2021.

Tous droits réservés 


\title{
Eugenia Fosalba (estudio y notas), El Abencerraje
}

\author{
Real Academia Española (Biblioteca Clásica de la Real Academia
}

Española, 33), Madrid, 2017

Daniel Fernández Rodríguez

\section{REFERENCIA}

Eugenia Fosalba (estudio y notas), El Abencerraje, edición, Madrid, Real Academia Española (Biblioteca Clásica de la Real Academia Española, 33), 2017, 353 p.

1 Considerada como la obra más representativa de la novela morisca, El Abencerraje se conserva en tres versiones distintas de mediados del siglo XVI, que Eugenia Fosalba pone ahora a disposición del público en una rigurosa edición crítica, cuyo propósito es devolver cada una de ellas «al lugar que le corresponde en relación con las demás: por esta razón se editan las tres, facilitando su consulta conjunta y sin regatear al lector la posibilidad de saborear los méritos propios de cada una» (p. 83). La edición de las tres versiones constituye ya de entrada y por sí mismo uno de los mayores atractivos del presente volumen, que se completa con un profundo análisis de la obra y varios anexos.

2 En su completísimo estudio introductorio, la editora se encarga en primer lugar de trazar los rasgos distintivos de cada una de esas tres versiones, ninguna de las cuales corresponde al texto original, si bien la más antigua, conocida como la Crónica, sería la más próxima. A pesar de lo cual apenas ha merecido la atención, y sí en cambio el desdén, por parte de críticos y editores, que tradicionalmente se han inclinado por la del poeta vallisoletano Antonio de Villegas, publicada en 1565 junto a otras obras del mismo autor bajo el título de Inventario, predilección en la que ha pesado sobre todo su estilo pulcro y cuidado. Menos fidelidad con respecto al original guarda la tercera en discordia, interpolada al final del capítulo cuarto de la Diana de Montemayor en la edición de 1561. La autoría de cada versión es el tema del que se ocupa el segundo apartado, con especial interés en la más antigua, desatendida hasta ahora por los 
estudiosos; de ahí la necesidad de una edición crítica y anotada de la misma, que la presente cumple con creces.

3 Compuesta en fecha que no pudo ser anterior a 1548, nada se sabe a ciencia cierta sobre quién fuera su autor. Al respecto, Eugenia Fosalba se inclina, con acopio de datos y sólida información, por Jerónimo Jiménez de Urrea, de cuya vida y obra ofrece un acabado perfil. Razones para tal atribución no le faltan, y el modo bien fundamentado con que las aduce redunda en la credibilidad de su apuesta; aun así, nos apercibe, se trata solo de una posibilidad, formulada «sin intención de incurrir en una defensa paladina» de la misma (p. 88).

4 Jiménez de Urrea, hijo ilegítimo del Vizconde de Biota, al que perdió muy pronto, probablemente se criara al amparo de los poderosos de la villa aragonesa de Épila, perteneciente al condado de Aranda y vecina de las baronías de Bárboles y Oitura, de las que era señor Jerónimo Jiménez Dembún, a quien está dedicada esta primera versión. Consejero y mano derecha del emperador en el reino de Aragón, Jiménez Dembún desempeñó un importante papel en favor de la convivencia pacífica de moriscos y cristianos en esas tierras, muy en consonancia con el espíritu de respeto y tolerancia que se respira en el Abencerraje, y bien pudo ser que se erigiera en valedor de su joven tocayo y le ayudara a entrar en los círculos de la corte. A ello contribuirían en gran medida los lazos de parentesco entre Urrea y su esposa doña Blanca de Sesé, lo que induce a conjeturar que «doña Blanca hubiera aconsejado a su marido recurrir a Jerónimo de Urrea para una obra de encargo que se ajustara a las necesidades de la circunstancia convulsa en Aragón a finales de los años cincuenta» (p. 92).

5 Nacido en torno a 1510, Urrea fue soldado poeta como Garcilaso -de cuya muerte en la fortaleza de Le Muy fue testigo- y se estableció, según parece a una edad temprana, en Italia, donde ocupó diversos cargos y participó en guerras y escaramuzas militares. Allí, en fecha y circunstancias desconocidas, encontró la muerte, y es muy posible que también allí escribiera sus obras, ninguna de las cuales vio la luz en las prensas españolas. Consta que entre 1562 y 1565 había terminado la más importante a nuestros efectos, el Diálogo de la verdadera honra militar, en la que aparece un personaje, con todo el aspecto de ser autobiográfico, que habla de su juvenil afición «por los viejos romances, los relatos caballerescos y la crónica de las guerras de Granada» (p. 93). Aparte de esbozar en uno de sus pasajes el tipo de militar sin ánimo belicoso que representa el moro Abindarráez en el Abencerraje, defiende que la verdadera honra militar reside en la clemencia con el derrotado; idea que se refleja claramente en el trato que Rodrigo de Narváez, el capitán cristiano, dispensa al citado Abindarráez cuando, tras curarle las heridas del combate y una vez que ha conocido de sus propios labios la causa de su verdadero dolor, le concede tres días de libertad para que acuda al encuentro de su amada Jarifa. El episodio referido a la conducta censurable del rey de Francia, que incumple su palabra luego de ser liberado por el emperador Carlos V, ilustra asimismo, por contraste, la conducta del musulmán, que, fiel a su promesa, regresa antes del tercer día.

6 De admitir la autoría propuesta por Fosalba, parece que Urrea o bien se desentendió del Abencerraje, cuya popularidad fue en aumento, o bien perdió el control sobre ella, algo que cabe achacar a su alejamiento de España o a que la Crónica se hubiera escrito por encargo o publicado sin su consentimiento. Esta circunstancia «propiciaría que la obra se plagiara y remozara sin obstáculos aparentes al menos por dos autores más, rivales entre sí a la vez que con Urrea, y ansiosos de ser aceptados en la corte española, como 
fueron Antonio de Villegas y Jorge de Montemayor» (p. 99), a quienes se deben la segunda y tercera versión. La enemistad personal y la competencia literaria entre ambos serían la causa de que en el Abencerraje de Villegas, publicado en 1565, no se adviertan rastros ni influencias de la versión de Montemayor, aparecida cuatro años antes, en 1561. Es más, «desde el punto de vista estrictamente textual es impensable que Villegas cotejara (para utilizarla como testimonio base) la versión de Montemayor al escribir la suya. La razón es muy simple: el texto que edita Villegas en su Inventario jamás se contamina con las muy abundantes amplificaciones de la versión de la Diana» (p. 120).

7 En resumen, las rivalidades y envidias personales y literarias, de las que no se libró tampoco Jiménez de Urrea, contribuyeron en buena medida a que el Abencerraje fuese considerado «desde el principio una obra comunal, en donde distintas imaginaciones se dieron alas para rivalizar. Razón esta por la que la obra, una auténtica tela de Penélope, ha llegado hasta nosotros en una mezcla casi inextricable de los trazos de varias plumas» (p. 122).

8 En el apartado siguiente, Trasfondo histórico del «Abencerraje», la profesora Fosalba trata de dilucidar «el fondo de verdad» (p. 122) tras el famoso linaje que se había convertido ya en un mito antes de dar nombre al libro. Empeño nada fácil, habida cuenta de «la complejísima historia del siglo XV granadino» (p. 123) y de la escasez de fuentes, árabes y cristianas, sobre este período, lo que ha obligado a recurrir a romances y leyendas. $Y$ estos, lo mismo que las crónicas castellanas, coinciden en otorgar a los Abencerrajes «el protagonismo que tienen en las versiones prosísticas del cuento que aquí se editan» (p. 124).

9 Por lo que atañe a los romances, particularmente a los fronterizos, si bien ninguno de los conservados refiere directamente los hechos que forman el núcleo de la novela, sí es posible rastrear en ellos alusiones a personajes, a nombres de lugar o a determinados sucesos. En cuanto a las crónicas que pudieran servir de fuentes, se cita entre otras la Relación de algunos sucesos de los últimos tiempos del reino de Granada de Hernando de Baeza, sin olvidar las de origen musulmán; se aportan asimismo datos pertinentes sobre personajes históricos que aparecen en la obra, como el infante don Fernando o Rodrigo de Narváez, alcaide de Antequera. De todo ello se concluye sin embargo «que no sabemos cuál pudo ser el núcleo primitivo que dio origen al relato tal y como se lee en las versiones que han llegado hasta nosotros. [...] Lo único que podemos afirmar con certeza es que el Abencerraje se escribió por los años en que se publicaron las primeras grandes antologías de romances» (p. 136).

Que la huella de la narrativa italiana es indudable queda bien probado con los ejemplos que la editora aduce con sabiduría y tino: pasajes de tinte amoroso de la Fiammetta y el Filocolo de Boccaccio, elementos bucólicos tomados de la Arcadia de Sannazaro. Estos rasgos de ascendencia italiana, junto con otros heredados de la tradición sentimental la pasión amorosa de dos personajes que desde niños se han criado como hermanos, el matrimonio clandestino propio de la novela de caballerías, reminiscencias de la fábula ovidiana de Píramo y Tisbe-, «ayudan a componer el cuadro de amor y naturaleza en el Abencerraje» (p. 145).

11 Se estudia a continuación, en magnífica y muy documentada síntesis, el impacto y proyección que tuvo en la literatura europea la historia de Abindarráez y la hermosa Jarifa. En España, luego de los primeros ecos aparecidos tempranamente en colecciones de romances, el caso más significativo al respecto son las Guerras civiles de Granada 
(1595) de Ginés Pérez de Hita, que «traslada el decorado seudohistórico de la frontera a la ciudad de Granada, multiplicando los recursos formales del Abencerraje inserto en la Diana, al complicar la casuística sentimental y alternar tiradas de prosa con numerosas composiciones poéticas (romances) y cartas» (pp. 145-146). Considerada por muchos como la primera novela histórica europea, esta obra supone la consagración del género y del «tipo literario del moro enamorado, ejemplo de elegancia moral» (p. 146). Para recrear el pasado, idealizándolo casi siempre, el autor echa mano con frecuencia de los romances fronterizos y, muy en particular, de los moriscos, que aparecieron con profusión en la década de 1580, unos y otros rastreados magistralmente por la editora. La sombra del Abencerraje alcanza también, como oportunamente se anota, a un puñado de comedias de Lope y a las novelas de María de Zayas y Castillo Solórzano.

En Europa fue la versión «pastoril» de la Diana, traducida a las lenguas más importantes, la que inspiró a lo largo del siglo XVII a poetas, narradores y dramaturgos. Así ocurrió en Francia, donde, luego de las tempranas ediciones, la primera de 1565, «muy pronto el Abencerraje llamó la atención por sí mismo»(p.161), y la figura ejemplar de Abindarráez contribuyó a mitificar el linaje de los nazaríes granadinos retratados en la obra de Pérez de Hita. Surge en este contexto, ya en la segunda mitad del siglo, el género maurófilo francés, que estrena Almahide ou l'esclave reine (1660-1663) de Madeleine de Scudéry, prosigue Madame de La Fayette con Zaïde (1670-1671) y pervive en el siglo XVIII; la impronta llega hasta Chateaubriand, que, en Les aventures $d u$ dernier Abencerage (1826), narra la historia de amor entre una cristiana y un moro.

La atracción que el tema morisco suscitó en Francia no se contagió ni a Italia ni a Inglaterra. En el país transalpino, «la conquista de Granada se adapta a la epopeya que estaba sentando sus bases tras el éxito de la Gerusalemme liberata de Tasso, con su propósito didáctico y su orientación decididamente cristiana (a través del motivo del asedio y conquista de una ciudad en poder de los infieles)» (p. 175). Inspirándose probablemente en la versión de la Crónica, Francesco Balbi di Correggio escribe en verso la primera obra sobre el tema, Historia de los amores del valeroso moro Abinde Araez y de la hermosa Xarifa Aben Cerases (1593), y a ella le siguen una de las Duecento novelle (1609) de Celio Malespini, basada en la versión de la Diana, y Della storia spagnuola i primi quattro libri (1640) de Anton Giulio Brignole Sale.

14 En Inglaterra, donde «la interpolación de la Diana apenas halló eco, pese a que desde 1598 circulaba la prestigiosa traducción de Bartholomew Yong que inspiró a Shakespeare varias comedias» (p. 179), únicamente el dramaturgo John Dryden trató el tema en su tragedia heroica The Conquest of Granada by the Spaniards (1670), para la que se inspiró principalmente en una fuente francesa, la Almahide de Scudéry.

El siguiente apartado, «Historia del texto», constituye un apasionante recorrido por los vericuetos y peripecias editoriales del Abencerraje. Tras mencionar brevemente los errores comunes que presentan los dos ejemplares conservados de la Crónica, los cuales revelan la existencia de cuando menos un arquetipo anterior a 1561, se exponen las razones que aconsejan optar como texto base por el ejemplar toledano de la Crónica en detrimento del de Cuenca, publicado, al igual que aquel, en 1561. A renglón seguido la editora va desgranando un conjunto de argumentos que, en contra de la que venía siendo opinión muy extendida, enseñan cómo la Crónica representa el testimonio más cercano al original. Entre las estrategias, muy reveladoras al respecto, practicadas por las otras versiones cabría citar la censura de pasajes eróticos presentes en la Crónica, el intento de subsanar algunos de sus errores manifiestos y la voluntad firme de pulir sus 
abundantes rasgos de oralidad, cuya reiterada aparición sugiere que la Crónica «se escribió (no resulta posible determinar si se compuso o reprodujo) al dictado» (p. 200). Se describe así, de un modo ameno y minucioso, el proceso de estilización que atraviesa el Inventario y culmina en la Diana, versión esta última que, como bien demuestra Fosalba, no solo manejó la Crónica, sino muy probablemente también un texto intermedio entre este testimonio y el Inventario.

A partir del estudio de las amplificaciones presentes en la versión de la Diana, que delatan a un autor muy seguro de sus dotes literarias y extremadamente familiarizado con el estilo de Montemayor, Fosalba emprende una sesuda comparación entre el usus scribendi de esta versión y el resto de la novela pastoril. El extraordinario acopio de casos y ejemplos de diversa índole deja poco lugar para la duda: el Abencerraje inserto en la Diana se debe a la pluma del propio Montemayor, tal y como la editora argumentara ya años atrás. $\mathrm{Y}$, dicho sea de paso, el pormenorizado estudio de esta versión permite además desechar o matizar el sambenito de "plagiario» que pesaba sobre el portugués, quien, en rigor, pulió y mejoró «esta joya literaria del siglo XVI, que parecía un relato histórico desgajado de alguna crónica, con la gracia añadida de cautivar a quien la leía merced a un dulce balanceo emocional y rítmico» (p. 251).

El volumen se completa con dos anexos sumamente útiles e interesantes: una selección de fragmentos de la primera parte de las Guerras civiles de Granada (1595) y la transcripción de la breve Historia del moro y Narváez, alcaide de Ronda, «versión en miniatura de la trama del Abencerraje» (p. 215) conservada en un manuscrito de finales del siglo XVI o principios del XVII.

18 En fin, esta edición del Abencerraje, llamada a convertirse en canónica, despeja las principales incógnitas de este pequeño tesoro de la literatura española, cuyas tres versiones se presentan y anotan con el rigor filológico y la claridad expositiva característicos de Eugenia Fosalba y de la colección Biblioteca Clásica. Así que bueno será dejarse caer por sus páginas $\mathrm{y}$, de la mano de su mejor conocedora, leer o releer, degustar o rememorar, alguno o cada uno de los tres Abencerrajes que aguardan al curioso lector y al esforzado especialista.

\section{AUTORES}

\section{DANIEL FERNÁNDEZ RODRÍGUEZ}

Université de Neuchâtel 